\title{
How long is the tail end of the learning curve? Results from 1000 consecutive endoscopic endonasal skull base cases following the initial 200 cases
}

\author{
Iyan Younus, BS, ${ }^{1}$ Mina M. Gerges, MD, ${ }^{2}$ Rafael Uribe-Cardenas, MD, MHS, ${ }^{2}$ \\ Peter F. Morgenstern, MD, ${ }^{2}$ Mahmoud Eljalby, MMSc, ${ }^{1}$ Abtin Tabaee, MD, ${ }^{3}$ \\ Jeffrey P. Greenfield, MD, PhD, ${ }^{2}$ Ashutosh Kacker, MD, ${ }^{3}$ Vijay K. Anand, MD, ${ }^{3}$ and \\ Theodore H. Schwartz, MD2-4
}

${ }^{1}$ Weill Cornell Medical College; and Departments of ${ }^{2}$ Neurosurgery, ${ }^{3}$ Otolaryngology, and ${ }^{4}$ Neuroscience, Weill Cornell Medicine, NewYork-Presbyterian Hospital, New York, New York

\begin{abstract}
OBJECTIVE Endoscopic endonasal approaches (EEAs) to the skull base have evolved over the last 20 years to become an essential component of a comprehensive skull base practice. Many case series show a learning curve from the earliest cases, in which the authors were inexperienced or were not using advanced closure techniques. It is generally accepted that once this learning curve is achieved, a plateau is reached with little incremental improvement. Cases performed during the early steep learning curve were eliminated to examine whether the continued improvement exists over the "tail end" of the curve.
\end{abstract}

METHODS A prospectively acquired database of all EEA cases performed by the senior authors at Weill Cornell Medicine/NewYork-Presbyterian Hospital was reviewed. The first 200 cases were eliminated and the next 1000 consecutive cases were examined to avoid the bias created by the early learning curve.

RESULTS Of the 1000 cases, the most common pathologies included pituitary adenoma (51\%), meningoencephalocele or CSF leak repair (8.6\%), meningioma (8.4\%), craniopharyngioma (7.3\%), basilar invagination (3.1\%), Rathke's cleft cyst $(2.8 \%)$, and chordoma (2.4\%). Use of lumbar drains decreased from the first half to the second half of our series $(p<0.05)$ as did the authors' use of fat alone $(p<0.005)$ or gasket alone $(p<0.005)$ for dural closure, while the use of a nasoseptal flap increased $(p<0.005)$. Although mean tumor diameter was constant (on average), gross-total resection (GTR) increased from $60 \%$ in the first half to $73 \%$ in the second half $(p<0.005)$. GTR increased for all pathologies but most significantly for chordoma ( $56 \%$ vs $100 \%, p<0.05$ ), craniopharyngioma ( $47 \%$ vs $0.71 \%, p<0.05$ ) and pituitary adenoma $(67 \%$ vs $75 \%, p<0.05)$. Hormonal cure for secreting adenomas also increased from $83 \%$ in the first half to $89 \%$ in the second half $(p<0.05)$. The rate of any complication was unchanged at $6.4 \%$ in the first half and $6.2 \%$ in the latter half of cases, and vascular injury occurred in only $0.6 \%$ of cases. Postoperative CSF leak occurred in $2 \%$ of cases and was unchanged between the first and second half of the series.

CONCLUSIONS This study demonstrates that contrary to popular belief, the surgical learning curve does not plateau but can continue for several years depending on the complexity of the endpoints considered. These findings may have implications for clinical trial design, surgical education, and patient safety measures.

https://thejns.org/doi/abs/10.3171/2019.12.JNS192600

KEYWORDS endonasal; endoscopic; transsphenoidal; follow-up; outcomes; learning curve; tail end; complication; gross-total resection; pituitary surgery

$\mathrm{E}$ NDOSCOPIC skull base surgery (ESBS) has rapidly gained acceptance over the past 2 decades as a minimally invasive approach for a variety of pathologies of the skull base. ${ }^{12,35}$ Recent technical advances in endoscopes, monitors, stereotaxy, the development of extended endonasal approaches, and reliable closure techniques have pushed the field into the forefront of modern skull base surgery.

In the early days of ESBS, several pioneers emphasized the steep learning curve, highlighting complications that

ABBREVIATIONS ACTH = adrenocorticotropic hormone; EEA = endoscopic endonasal approach; ESBS = endoscopic skull base surgery; GH = growth hormone; GTR = gross-total resection; RCC = Rathke's cleft cyst.

SUBMITTED September 20, 2019. ACCEPTED December 2, 2019.

INCLUDE WHEN CITING Published online February 7, 2020; DOI: 10.3171/2019.12.JNS192600. 
can occur for the novice practitioner. ${ }^{5,20,21}$ As the field evolved, the concept of a learning curve became less critical and the focus was shifted to the safety and efficacy of the approach as compared to microscopic and open transcranial approaches..$^{15-19}$ The classic surgical learning curve is S-shaped with a tail end that plateaus and supposedly becomes flat, indicating mastery. ${ }^{13,32}$ However, in a complex field such as neurosurgery, it is possible that with continued effort and improvement, the learning curve will persist even after several hundred cases. In this paper, we examine outcomes and complications in a consecutive series of 1000 ESBS cases. With an understanding of which outcomes continue to improve, which decline, and which plateau, will come a greater understanding of which areas require persistent and potentially unending practice and which areas may benefit from novel strategies for improvement.

\section{Methods}

\section{Patient Population and Surgical Approach}

We analyzed a prospectively acquired database of a consecutive series of surgeries utilizing the endoscopic endonasal approach (EEA) from 2004 to 2018 at NewYorkPresbyterian Hospital, Weill Cornell Medicine. From these cases, the first 200 cases were eliminated and considered part of our learning curve. The study was approved by our IRB. All surgeries were performed by the senior author (T.H.S.). Technical aspects of surgery remained relatively consistent for all cases. Specifically, every case was assisted by an otolaryngologist and by either a resident or a fellow. There were no technical innovations or major instrument changes introduced during the course of this series. The use of the gasket seal, nasoseptal flap, and endonasal bipolar cauterization all occurred after the first 200 cases, which is why they were eliminated. A detailed description of our EEA technique for a variety of skull base lesions has been extensively reported. ${ }^{34}$ We have also previously described an algorithm for reconstruction of the skull base and a case-specific protocol to reduce CSF leak after ESBS. ${ }^{26,31,41}$ Our gasket-seal closure and nasoseptal flap reconstruction protocols have also been described in detail. $8,24,26,28$

\section{Patient Demographics, Clinical Characteristics, and Complications}

Our institution began utilizing a prospective passwordprotected database of all EEA cases in which the senior neurosurgeon (T.H.S.) entered the following data immediately after surgery and for the duration of the patients' hospital stay until the final pathology returned: name, medical record number, date of surgery, final pathology, approach (sinus opened), use of lumbar drainage, use of intrathecal fluorescein, presence of intraoperative CSF leak, closure technique/graft materials used, and occurrence of postoperative CSF leak. Additional data collected and analyzed retrospectively for each case included the patient's sex, age, follow-up period, procedure length, radiographic extent of resection based on review of postoperative MRI by a board certified neuroradiologist performed within a week after surgery, previous surgery, previous radiation, confirmation of final pathology, endocrine outcomes, and complications. Complete biochemical remission for prolactinomas was determined by normalization of serum prolactin levels $<20 \mu \mathrm{g} / \mathrm{L}$; for growth hormone $(\mathrm{GH})-$ producing tumors, by normalization of serum $\mathrm{GH}<1 \mu \mathrm{g} / \mathrm{L}$ or nadir GH after oral glucose tolerance test $\leq 0.4 \mu \mathrm{g} / \mathrm{L}$; and for adrenocorticotropic hormone (ACTH)-producing tumors, by morning serum cortisol levels $<3 \mu \mathrm{g} / \mathrm{dl} 3-5$ days after surgery. Complications were tracked in the immediate postoperative period and at long-term follow-up. Infections were reported as confirmed meningitis or other infection. In cases in which meningitis was suspected, CSF samples were collected and cultured. Neurological deficits were reported as specific cranial nerve palsy when applicable. Vascular injuries were reported based on the vessel involved. Postoperative CSF leak was defined as clear CSF rhinorrhea, confirmed by the senior author, where reoperation was required for repair.

\section{Statistical Analysis}

The SPSS statistical software package (version 24, IBM Corp.) was utilized for all analyses. Univariate analysis was performed using Pearson chi-square and Fisher's exact tests for categorical variables, and the independentsamples t-test for continuous variables. For all tests, statistical significance was determined with an alpha level $<0.05$.

\section{Results \\ Patient Demographics and Clinical Characteristics}

A consecutive series of 1000 cases that underwent EEA for more than 40 different skull base pathologies were included in the study. The cohort comprised $52 \%$ females and $48 \%$ males. There was no statistically significant difference in sex between the first 500 and latter 500 cases in the cohort (Table 1). The mean patient age was $50 \pm 18$ years and $23 \%$ were over the age of 65 years. The mean patient age was $50.5 \pm 18$ years for the first half versus 49.5 \pm 18 years for the latter half of the cohort. Reoperations accounted for $15 \%$ of cases in the first half of the cohort compared to $16 \%$ of cases in the latter half. Gross-total resection (GTR) was achieved in $67 \%$ of 827 cases in which it could be assessed. GTR was accomplished in $60 \%$ of 400 applicable cases in the first half compared to $73 \%$ of 427 applicable cases in the latter half of the cohort ( $\mathrm{p}$ $<0.005$ ). The mean follow-up duration for the cohort was $707 \pm 849$ days. The mean procedure length was significantly longer for cases in the latter half ( $247 \pm 108$ mins) compared to the first half $(224 \pm 101$ mins, $p<0.05)$ of the cohort. The mean procedure length based on pathology is summarized in Fig. 1A.

\section{Pathology and Surgical Approaches}

The most common pathology encountered was pituitary adenoma (51\%, Table 2). Other pathologies encountered were meningoencephalocele/CSF leak repair $(8.6 \%)$, meningioma $(8.4 \%)$, craniopharyngioma $(7.3 \%)$, basilar invagination (3.1\%), Rathke's cleft cyst (RCC; $2.8 \%$ ), chordoma (2.4\%), other malignancies $(2.2 \%)$, and metastasis (1.6\%). Pathologies performed more frequently 
TABLE 1. Comparison between the first- and latter-half cases

\begin{tabular}{|c|c|c|c|}
\hline Variable & $\begin{array}{l}\text { First } 500 \\
\text { Cases (\%) }\end{array}$ & $\begin{array}{l}\text { Last } 500 \\
\text { Cases (\%) }\end{array}$ & $p$ Value \\
\hline \multicolumn{4}{|l|}{ Sex } \\
\hline Females & $263(53)$ & $253(51)$ & NS \\
\hline Males & $237(47)$ & $247(49)$ & NS \\
\hline Mean age $\pm S D$, yrs & $50.5 \pm 18$ & $49.5 \pm 18$ & NS \\
\hline Reoperations & $73(15)$ & $78(16)$ & NS \\
\hline GTR & $238 / 400(60)$ & $312 / 427(73)$ & $<0.005$ \\
\hline $\begin{array}{l}\text { Mean procedure length } \pm \\
\text { SD, mins }\end{array}$ & $224 \pm 101$ & $247 \pm 108$ & $<0.05$ \\
\hline Intraop CSF leak & $299(60)$ & $255(51)$ & NS \\
\hline \multicolumn{4}{|l|}{ Lumbar drain } \\
\hline In all patients & $162(32)$ & $79(16)$ & $<0.005$ \\
\hline $\begin{array}{l}\text { In patients w/ intraop } \\
\text { CSF leak }\end{array}$ & $162 / 299(54)$ & $79 / 255(31)$ & $<0.005$ \\
\hline Any complication & $32(6.4)$ & $31(6.2)$ & NS \\
\hline Postop CSF leak & $10(2)$ & $10(2)$ & NS \\
\hline Neurological deficit & $8(1.6)$ & $13(2.6)$ & NS \\
\hline Infection & $8(1.6)$ & $8(1.6)$ & NS \\
\hline Hematoma & $5(1)$ & $7(1.4)$ & NS \\
\hline Vascular injury & $3(0.6)$ & 0 & NS \\
\hline DVT/PE & $4(0.8)$ & 0 & NS \\
\hline Mortality & $1(0.2)$ & $1(0.2)$ & NS \\
\hline
\end{tabular}

DVT/PE = deep vein thrombosis/pulmonary embolism; NS = not significant. Boldface type indicates statistical significance. in the second half of the series were basilar invagination ( $p<0.005)$ and RCC ( $\mathrm{p}<0.05$ ), while cases performed less frequently were meningoencephalocele/CSF leak repair $(\mathrm{p}<0.005)$ and chordoma ( $<<0.005$; Table 2). The remaining pathologies all had a frequency $<1 \%$. The most common approach was transellar (46\%), which was performed more commonly in the latter half compared to the first half of the cohort (54\% vs 46\%, p <0.05). Other approaches were transplanum (27\%), transclival (7.5\%), transcribriform (6.4\%), transethmoidal (4.4\%), transpterygoid (4.3\%), transodontoid (3.4\%), and transorbital (1.2\%). The transclival and transcribriform approaches were both more commonly performed in the first half compared to the latter half of the cohort ( $\mathrm{p}<0.005)$. The transodontoid approach was significantly more common in the latter half compared to the first half of the cohort ( $74 \%$ vs $26 \%$, $\mathrm{p}<0.005$ ).

\section{Extent of Resection Based on Pathology}

The overall rate of GTR for pituitary adenomas was $71 \%$ (67\% first half vs $75 \%$ latter half, p <0.05; Fig. 2B). The overall rate of GTR for meningiomas was $63 \%$ (55\% first half vs $70 \%$ latter half, $p=0.18$ ). The overall rate of GTR for craniopharyngioma cases was $62 \%$ (47\% first half vs $71 \%$ latter half, $\mathrm{p}<0.05$ ). The overall rate of GTR for chordoma cases was $67 \%$ (56\% vs $100 \%$ for the first half vs latter half of cases, respectively; $p<0.05$ ). GTR was not included for odontoid resection, in which the goal of surgery was decompression of the cord, or RCC, in which the goal of surgery was fenestration. When excluding reoperations and analyzing only first-time operations, the overall rate of GTR for pituitary adenomas was $73 \%$
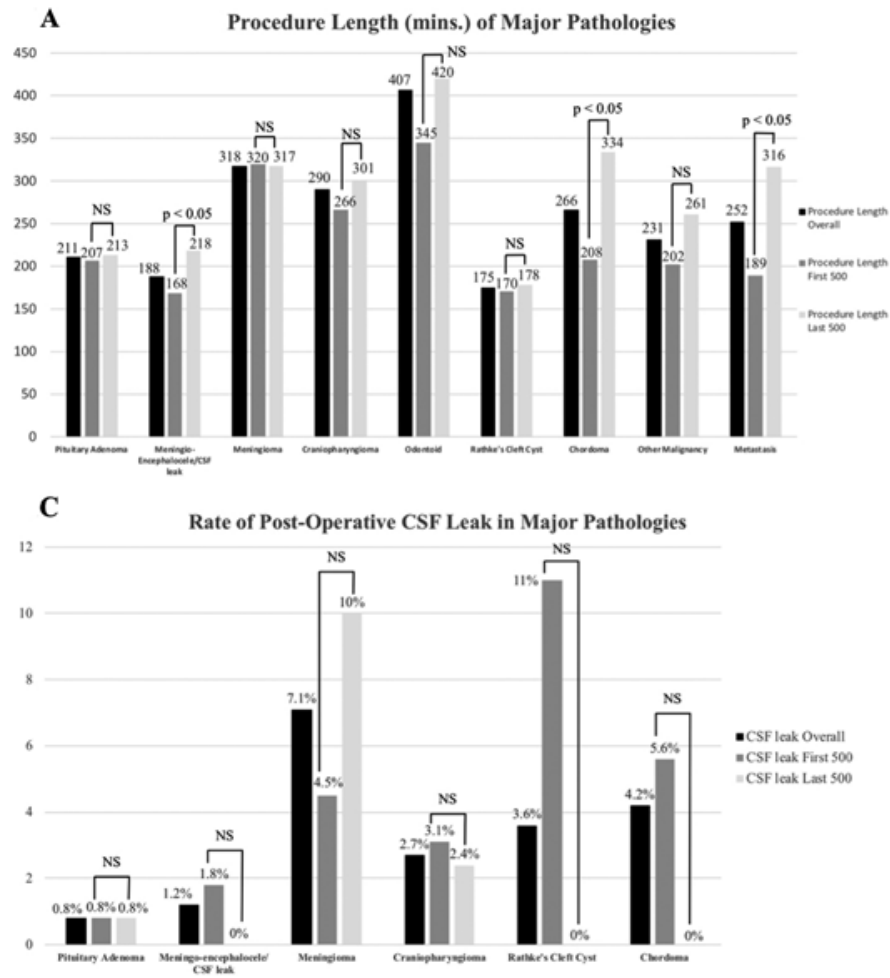

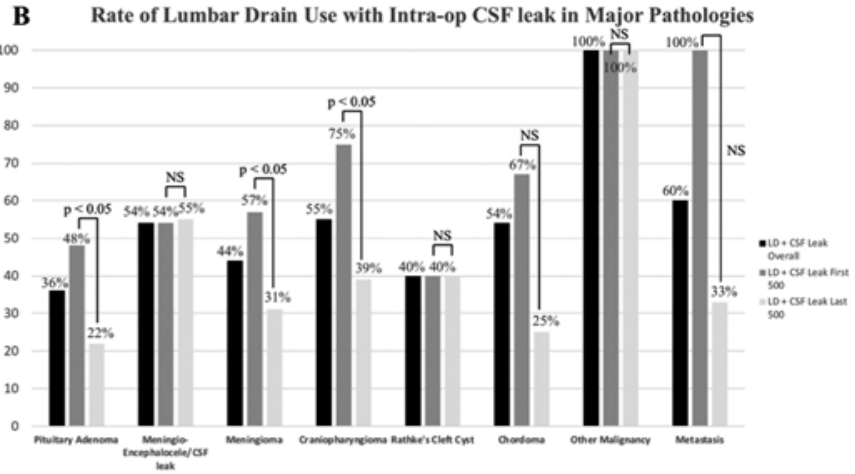

FIG. 1. Comparison of overall (black bars), first 500 (dark gray bars), and latter 500 cases (light gray bars). A: Procedure length was significantly longer for meningoencephalocele/CSF leak repair, chordoma, and metastasis in the latter half of the cohort compared to the first half $(p$ $<0.05)$. B: Rate of lumbar drain use in patients with intraoperative CSF leak was significantly lower for pituitary adenoma, meningioma, and craniopharyngioma in the latter half of the cohort compared to the first half $(p<0.05)$. C: Rate of postoperative CSF leak showed no significant differences between the first half and latter half of the cohort for major pathologies. NS = not significant. 
TABLE 2. Summary of pathologies in 1000 EEA cases

\begin{tabular}{|c|c|c|c|c|}
\hline Pathology & Overall (\%) & First $500(\%)$ & Last $500(\%)$ & p Value \\
\hline Pituitary adenoma & $514(51)$ & $246(48)$ & $268(52)$ & NS \\
\hline Meningoencephalocele/CSF leak repair & $86(8.6)$ & $57(66)$ & $29(34)$ & $<0.005$ \\
\hline Meningioma & $84(8.4)$ & $44(52)$ & $40(48)$ & NS \\
\hline Craniopharyngioma & $73(7.3)$ & $32(44)$ & $41(56)$ & NS \\
\hline Basilar invagination & $31(3.1)$ & $6(19)$ & $25(81)$ & $<0.005$ \\
\hline RCC & $28(2.8)$ & $9(32)$ & $19(68)$ & $<0.05$ \\
\hline Chordoma & $24(2.4)$ & $18(75)$ & $6(25)$ & $<0.005$ \\
\hline Other malignancies & $22(2.2)$ & $13(59)$ & $9(41)$ & NS \\
\hline Metastasis & $16(1.6)$ & $7(44)$ & $9(56)$ & NS \\
\hline Epidermoid & $9(<1)$ & $4(44)$ & $5(56)$ & NS \\
\hline Xanthogranuloma & $9(<1)$ & $4(44)$ & $5(56)$ & NS \\
\hline Fibroma & $8(<1)$ & $5(62)$ & $3(38)$ & NS \\
\hline Lymphoma & $8(<1)$ & $6(75)$ & $2(25)$ & NS \\
\hline Chondrosarcoma & $7(<1)$ & $4(57)$ & $3(43)$ & NS \\
\hline Angiofibroma & $7(<1)$ & $6(86)$ & $1(14)$ & $<0.05$ \\
\hline Squamous cell carcinoma & $7(<1)$ & $2(29)$ & $5(71)$ & NS \\
\hline Hemangioma & $6(<1)$ & $4(67)$ & $2(33)$ & NS \\
\hline Mucocele & $5(<1)$ & $3(60)$ & $2(40)$ & NS \\
\hline Schwannoma & $5(<1)$ & $4(80)$ & $1(20)$ & NS \\
\hline Esthesioneuroblastoma & $4(<1)$ & $1(25)$ & $3(75)$ & NS \\
\hline Arachnoid cyst & $3(<1)$ & $2(67)$ & $1(33)$ & NS \\
\hline Cholesteatoma & $3(<1)$ & $2(67)$ & $1(33)$ & NS \\
\hline Clival mass unknown & $3(<1)$ & $2(67)$ & $1(33)$ & NS \\
\hline Germinoma & $3(<1)$ & $1(33)$ & $2(67)$ & NS \\
\hline Hemangiopericytoma & $3(<1)$ & $2(67)$ & $1(33)$ & NS \\
\hline Plasmacytoma & $3(<1)$ & $1(33)$ & $2(67)$ & NS \\
\hline Rhabdomyosarcoma & $3(<1)$ & $1(33)$ & $2(67)$ & NS \\
\hline Neurosarcoidosis & $3(<1)$ & $1(33)$ & $2(67)$ & NS \\
\hline Dermoid & $2(<1)$ & $1(50)$ & $1(50)$ & NS \\
\hline Chondromyxoid fibroma & $2(<1)$ & 0 & $2(100)$ & NS \\
\hline Ependymoma & $2(<1)$ & $2(100)$ & 0 & NS \\
\hline Hypophysitis & $2(<1)$ & 0 & $2(100)$ & NS \\
\hline Inverted papilloma & $2(<1)$ & $2(100)$ & 0 & NS \\
\hline Osteomyelitis & $2(<1)$ & $1(50)$ & $1(50)$ & NS \\
\hline Optic nerve pathology & $2(<1)$ & $1(50)$ & $1(50)$ & NS \\
\hline Pituicytoma & $2(<1)$ & $1(50)$ & $1(50)$ & NS \\
\hline Pituitary carcinoma & $2(<1)$ & $2(100)$ & 0 & NS \\
\hline Aspergilloma & $1(<1)$ & $1(100)$ & 0 & NS \\
\hline Epithelioid hemangioendothelioma & $1(<1)$ & 0 & $1(100)$ & NS \\
\hline Fibrosarcoma & $1(<1)$ & $1(100)$ & 0 & NS \\
\hline Enterogenous cyst & $1(<1)$ & $1(100)$ & 0 & NS \\
\hline Phlegmon & $1(<1)$ & $1(100)$ & 0 & NS \\
\hline
\end{tabular}

Boldface type indicates statistical significance.

(68\% first half vs $78 \%$ latter half, $\mathrm{p}<0.05$ ), for meningiomas $81 \%$ ( $80 \%$ first half vs $83 \%$ latter half), for craniopharyngiomas $74 \%$ (59\% first half vs $88 \%$ latter half, p $<0.05$ ), and for chordomas $70 \%$ (53\% first half vs 100\% [n $=6]$ latter half).

\section{Intraoperative CSF Leak Based on Pathology and Closure Type}

Intraoperative CSF leak occurred in $52 \%$ of cases. Rates of intraoperative CSF leaks based on pathology are summarized in Table 3 . The rate of intraoperative CSF 

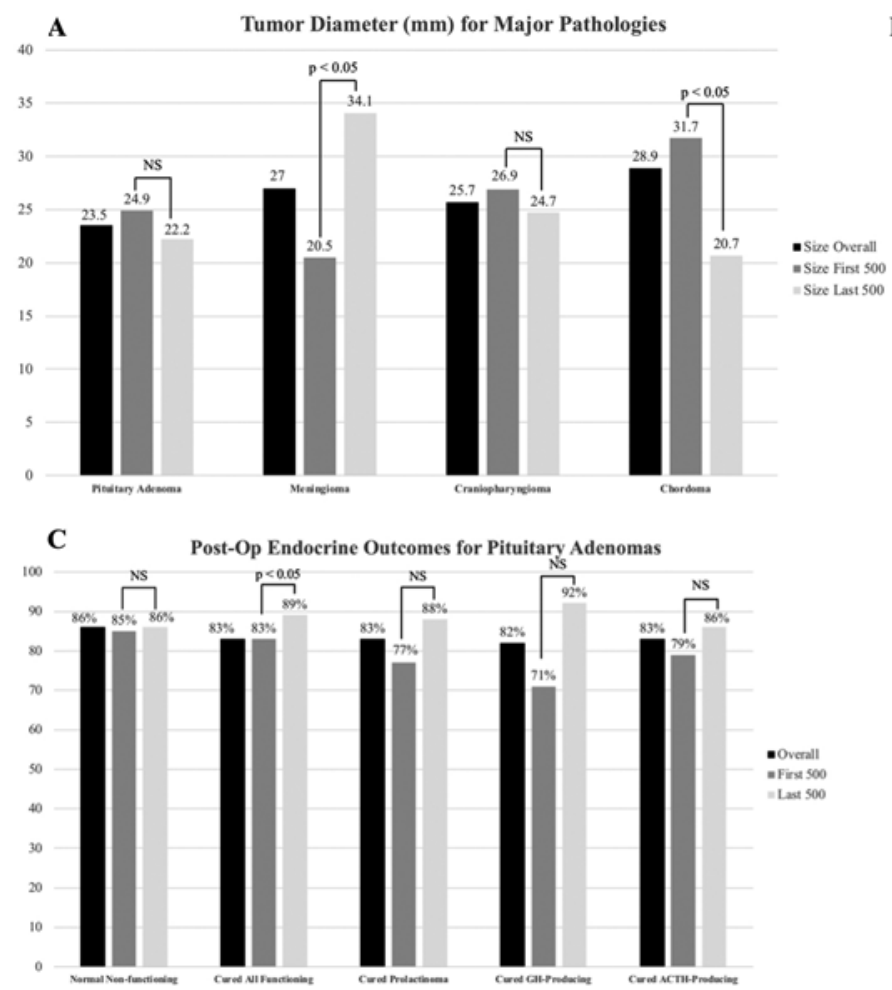

leak significantly decreased only for pituitary adenomas in the latter half of the cohort compared to the first half ( $40 \%$ vs $52 \%, \mathrm{p}<0.05)$. The most common type of closure was nasoseptal flap with fat $(25 \%)$ and was associated with a $2 \%$ rate of postoperative CSF leak (Table 4). This closure was most commonly used for pituitary adenoma (61\%) followed by meningoencephalocele (16\%). Closure with fat only was performed in $19 \%$ and associated with a $2.1 \%$ rate of CSF leak. Closure using fat only was significantly more common in the first half of the cohort compared to the latter half ( $77 \%$ vs $23 \%$, p <0.005). This closure was generally used for pituitary adenomas (64\%) and meningoencephalocele/CSF leak repair (13\%). Gasket seal closure with nasoseptal flap and fat was per-

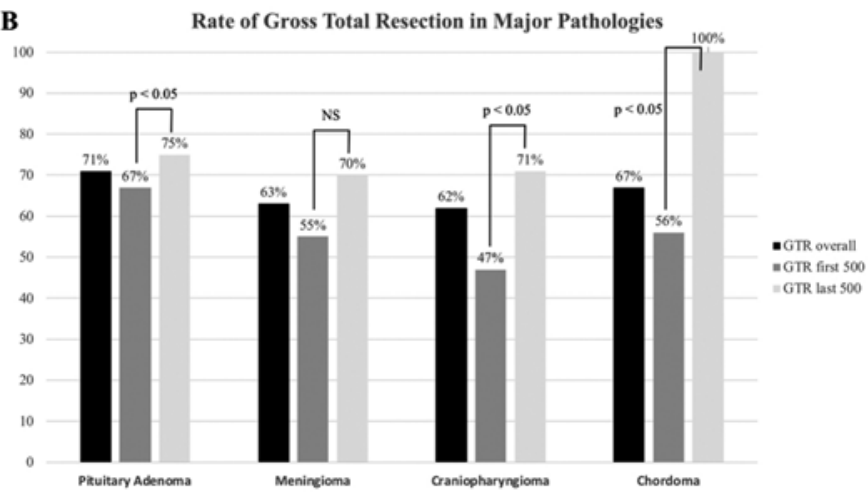

FIG. 2. Comparison of overall (black bars), first 500 (dark gray bars), and latter 500 cases (light gray bars). A: Tumor diameter was significantly larger for meningiomas in the latter-half cases compared to the first half $(p<0.05)$. Tumor diameter was significantly larger for chordomas in the first-half cases compared to the latter half $(p<0.05)$. B: The rate of GTR was significantly higher for pituitary adenoma, craniopharyngioma, and chordoma in the latter half of the cohort compared to the first half ( $p$ $<0.05)$. C: For nonfunctioning adenomas, $86 \%$ had normal endocrine status at last follow-up with no change over time ( $85 \%$ first half vs $86 \%$ latter half). Cure rates for hormone-producing tumors increased significantly over time when grouped together $(p<0.05)$.

formed in $19 \%$ of cases and associated with a $3.6 \%$ rate of CSF leak. This closure was the most commonly used for craniopharyngiomas (29\%), meningiomas (26\%), and pituitary adenomas (26\%). Closure with Gelfoam alone or nothing was performed in $19 \%$ of cases and associated with a $0.5 \%$ rate of CSF leak. Closure with Gelfoam alone or nothing was also significantly more common in the latter half of the cohort compared to the first half (63\% vs $37 \%, p<0.005)$. This type of closure was generally used when there was no intraoperative CSF leak and depending on the amount of bleeding. Closure with a nasoseptal flap only was performed in $14 \%$ of cases, mostly in pituitary adenomas (63\%), and was associated with no postoperative CSF leaks. Closure with a nasoseptal flap

TABLE 3. Major pathologies and rate of intraoperative CSF leak

\begin{tabular}{lrrrr}
\hline \multirow{2}{*}{ Pathology } & \multicolumn{3}{c}{ Intraop CSF Leak } & \multirow{2}{*}{ p Value } \\
\cline { 2 - 4 } & Overall (\%) & First 500 (\%) & Last 500 (\%) & $<0.05$ \\
\hline Pituitary adenoma & $234 / 514(46)$ & $127 / 246(52)$ & $107 / 268(40)$ & NS \\
\hline Meningoencephalocele/CSF leak repair & $70 / 86(81)$ & $48 / 57(84)$ & $22 / 29(76)$ & NS \\
\hline Meningioma & $70 / 84(83)$ & $35 / 44(80)$ & $35 / 40(88)$ & NS \\
\hline Craniopharyngioma & $73 / 73(100)$ & $32 / 32(100)$ & $41 / 41(100)$ & NS \\
\hline Odontoid & $4 / 31(13)$ & $0 / 6(0)$ & $4 / 25(16)$ & NS \\
\hline RCC & $10 / 28(36)$ & $5 / 9(56)$ & $5 / 19(26)$ & NS \\
\hline Chordoma & $13 / 24(54)$ & $9 / 18(50)$ & $4 / 6(67)$ & NS \\
\hline Other malignancies & $7 / 22(32)$ & $4 / 13(31)$ & $3 / 9(33)$ & NS \\
\hline Metastasis & $10 / 16(63)$ & $4 / 7(57)$ & $6 / 9(66)$ & NS \\
\hline Boldface type indicates statistical significance. & & &
\end{tabular}


TABLE 4. Summary of closure technique and rate of postoperative CSF leak

\begin{tabular}{lccccc}
\hline \multicolumn{1}{c}{ Closure } & Overall (\%) & First 500 (\%) & Last 500 (\%) & p Value & CSF Leak (\%) \\
\hline Nasoseptal flap \pm fat or fascia lata & $245(25)$ & $124(51)$ & $121(49)$ & NS & $5(2)$ \\
\hline Fat & $193(19)$ & $149(77)$ & $44(23)$ & $<0.005$ & $4(2.1)$ \\
\hline Gasket + nasoseptal flap + fat or fascia lata & $192(19)$ & $88(46)$ & $104(54)$ & NS & $7(3.6)$ \\
\hline Gelfoam only, or nothing & $186(19)$ & $68(37)$ & $118(63)$ & $<0.005$ & $1(0.5)$ \\
\hline Nasoseptal flap & $150(15)$ & $59(39)$ & $91(61)$ & $<0.005$ & 0 \\
\hline Nothing & $71(7.1)$ & $32(45)$ & $39(55)$ & NS & $1(1.4)$ \\
\hline Gasket \pm fat or fascia lata (no nasoseptal flap) & $23(2.3)$ & $23(100)$ & 0 & $<0.005$ & $3(13)$ \\
\hline Fat + middle turbinate flap & $11(1.1)$ & $5(45)$ & $6(55)$ & NS & 0 \\
\hline
\end{tabular}

Boldface type indicates statistical significance.

increased significantly in the latter half of the cohort compared to the first half $(61 \%$ vs $39 \%$, p <0.005). Gasket seal closure alone with fat was performed in $2.3 \%$ of cases, all of which were in the first half of the cohort $(\mathrm{p}<0.005)$, and was associated with a $13 \%$ rate of postoperative CSF leak. In the latter half of our series we never used a gasket alone and always combined it with a flap. Closure with no graft other than dural sealant was performed in $7.1 \%$ of cases and associated with a $1.4 \%$ rate of CSF leak. Closure with a middle turbinate flap and fat was performed in $1.1 \%$ of cases and associated with no CSF leaks. This closure was often used with meningoencephalocele/CSF leak repair $(64 \%)$.

\section{Use of Lumbar Drains}

We used a lumbar drain in $24 \%$ of our cases (32\% first half vs $16 \%$ latter half, $\mathrm{p}<0.05$; Table 1$)$. Based on pathology, lumbar drains were used in pituitary adenoma (17\%), meningioma (37\%), craniopharyngioma (55\%), meningoencephalocele/CSF leak repair (44\%), RCC (14\%), chordoma (29\%), other malignancies (32\%), and metastasis $(38 \%)$. The rate of lumbar drain use in pituitary adenomas significantly decreased between the first half and latter half of the cohort $(25 \%$ vs $9 \%, \mathrm{p}<0.05)$. The rate of lumbar drain use in craniopharyngioma $(75 \%$ vs $39 \%$, $\mathrm{p}<0.05)$ and metastasis $(57 \%$ vs $13 \%, \mathrm{p}<0.05)$ also significantly decreased between the first half and latter half of the cohort, respectively. Usage of a lumbar drain also

\section{TABLE 5. Summary of complications}

\begin{tabular}{cc}
\hline Complication & Value (\%) \\
\hline Any complication & $63(6.3)$ \\
\hline Neurological deficit & $21(2.1)$ \\
\hline Postop CSF leak & $20(2)$ \\
\hline Any infection & $16(1.6)$ \\
\hline Meningitis & $6(0.6)$ \\
\hline Hematoma & $12(1.2)$ \\
\hline DVT/PE & $4(0.4)$ \\
\hline Vascular injury & $3(0.3)$ \\
\hline Mortality & $2(0.2)$ \\
\hline
\end{tabular}

Some patients had more than one complication. decreased in all other pathologies between the first half and latter half of the cases, although the difference was not statistically significant. Using the denominator of intraoperative CSF leak, lumbar drains were used in $42 \%$ of patients (54\% first half vs $31 \%$ latter half, $\mathrm{p}<0.005$; Table 1). Based on pathology as well as presence of intraoperative CSF leak, lumbar drain use is summarized in Fig. 1B.

\section{Complications Excluding CSF Leaks}

Postoperative complications occurred in $6.3 \%$ of cases (Table 5). The rate of any complication was $6.4 \%$ in the first half and $6.2 \%$ in the latter half of cases. The most common complication was neurological deficit occurring in $2.1 \%$ cases. Neurological deficit was present in $1.6 \%$ of cases in the first half of the cohort compared to $2.6 \%$ of cases in the latter half of the cohort. The most commonly encountered neurological deficits were from visual loss (14 patients) or cranial nerve palsy (7 patients). Cranial verve VI palsy occurred in 4 cases and cranial nerve III palsy occurred in 3 patients. Infection, either intracranial or extracranial, occurred in $1.6 \%$ of cases. The rate of infection was $1.6 \%$ in both the first half and latter half of the cohort. Systemic infections including urinary tract infection, urosepsis, and bacteremia accounted for $1 \%$ of cases and meningitis accounted for $0.6 \%$ of cases. Postoperative hematoma requiring reoperation occurred in $1.2 \%$ of cases, with pituitary adenoma accounting for the majority ( $\mathrm{n}=$ 9) of cases. Other cases requiring reoperation for hematoma were craniopharyngioma (1 patient), meningioma (1 patient), and RCC (1 patient). The rate of hematoma was $1 \%$ in the first half of the cohort compared to $1.4 \%$ in the latter half of the cohort. Vascular injury occurred in $0.6 \%$ of cases, involving the internal carotid artery in 2 cases and the ophthalmic artery in 1 case. Pulmonary embolism occurred in $0.8 \%$ of patients and mortality in $0.2 \%$ of cases caused by dilated cardiomyopathy (1 patient) and metastatic prostate cancer (1 patient). The rate of vascular injury, pulmonary embolism, and mortality was $<1 \%$ for both the first half and latter half of the cohort.

\section{Rate of Postoperative CSF Leak}

Postoperative CSF leak requiring reoperation occurred in 20 cases (2\%). Postoperative CSF leak was $2 \%$ in both the first half and latter half of cases. Revision of dural closure was performed in all cases. The overall rate of post- 
operative CSF leak based on pathology is summarized in Fig. 1C.

\section{Tumor Size}

The mean tumor diameter for the entire cohort of tumors was $24.6 \pm 11.4 \mathrm{~mm}$ and did not change from the first half to the second half $(25.5 \pm 10.8 \mathrm{~mm}$ vs $24.2 \pm$ $11.8 \mathrm{~mm}$ ). The mean tumor diameter based on pathology is summarized in Fig. 2A.

\section{Endocrine Outcomes}

Nonfunctioning adenomas accounted for $73 \%$ of all pituitary adenomas. The remainder were prolactinomas (10.5\%), GH (9.7\%), and ACTH (6.8\%) producing. For nonfunctioning adenomas, $86 \%$ had normal endocrine status at last follow-up with no change over time (85\% first half vs $86 \%$ latter half). Cure rates for hormone-producing tumors increased significantly over time when grouped together $(\mathrm{p}<0.05)$. Endocrine outcomes for functioning and nonfunctioning pituitary adenomas are summarized in Fig. 2C.

\section{Discussion}

The article reports the largest series of consecutive EEA cases reported in the literature and the only study that documents incremental changes in surgical outcome that can occur during the presumed "plateau" or "tail end" of the learning curve after a large number of cases. Although the steep initial learning curve in ESBS cases has been extensively reported in the literature by our group and others, ${ }^{4,10}$, $14,20,25,27,30,31,33,37,39$ there are few data on the tail end of the learning curve in EEA surgeries, or any neurosurgical procedures for that matter. While most previously published studies examine the initial learning curve in ESBS, we eliminated our first 200 cases to focus uniquely on the tail end of the curve. The main finding in this study is that the tail end of the learning curve evolves differently depending on the outcome measure being examined. More specifically, complex outcomes such as GTR rates and hormonal cure continued to improve even after 700 cases, while other outcomes such as complications, CSF leak rates, and hormone preservation in non-hormone producing tumors remained stable. An increase in GTR and hormonal cure cannot merely be attributed to environment, because case complexity can be assumed to increase over time, caused by an increase in the daring of the surgeon to tackle more difficult cases as well as increased rate of complex case referrals from other nearby centers that may have less experience. Likewise, there were no new technical advances in equipment that could explain our improvements. The most likely explanation is that the technical ability and judgment required to master a complex skill such as achieving a GTR in an EEA case requires a significant amount of time and has a long, slow learning curve. Whether such a long, drawn-out learning curve exists for all complex surgical procedures or is unique to ESBS and its implications will be discussed.

\section{Steep Early Learning Curve}

The early learning curve in surgical training has been a focus of study in all fields of surgery. The classic learning curve, originally described in aircraft manufacturing, has an S-shape with three stages (Fig. 3). ${ }^{43}$ The first stage involved slow acquisition of new skills, the second phase a rapid increase in proficiency, and the last stage a plateau indicating mastery. ${ }^{1,6,11,13,22,32,36,38,44}$ One of the primary goals of studying the surgical learning curve is to establish a minimum number of cases after which a surgeon can be considered "proficient" in their specialty., The slope of the early learning curve is dependent on the skill of the trainee, the complexity of the procedure, and the number of repetitions. ${ }^{40}$ ESBS is no exception and several reports have described the early learning curve. The conclusion of these studies is that over the course of the first 50-200 cases, most centers noticed a decrease in postoperative CSF leaks and operative time as well as an increase in extent of resection, after which results tend to plateau. ${ }^{4,5,10,20 \text {, }}$ 21,33,37 Nix et al. examined the success of skull base closure and found that there was a learning curve only for complex skull base closure for high-flow leaks, indicating that complexity may be a factor in the learning curve. ${ }^{27}$

These studies on the early learning curve not only fail to examine the tail end of the curve but also reveal one of the major criticisms of learning-curve evaluation, namely the differential effect of skill acquisition on different outcome variables. Two main types of variables are generally studied, either the surgical process or patient outcomes. ${ }^{13}$ The former includes length of the procedure, success of the procedure, and extent of resection, and the latter includes blood loss, length of stay, complications, and survival. The most common variable measured is also the easiest to measure, namely procedure length. However, procedure length is often not a good measure of outcome. In fact, several studies of procedure length have demonstrated that the classic S-shaped curve fails to adequately characterize operative duration because surgeons tend to take on more complex cases and spend more time teaching once they gain proficiency, so operative time may increase at the tail end of the curve (Fig. 3). ${ }^{32}$ Our data confirm this finding. However, as we show in our data, some outcome measures demonstrate a plateau while others continue to improve even after hundreds of cases. More specifically, complications and CSF leak can be stabilized based on algorithms and standard critical pathways for managing postoperative patients. However, the skill set, experience, and anatomical knowledge required to perform delicate microdissection around critical neurovascular structures defies most systematized or regimented teaching curricula and cannot be reduced to an algorithm. Simulations and cadavers can provide some of the required practice venues but do not adequately mimic the complexity, feel, and stakes of actual surgery.

\section{Tail End of the Learning Curve}

There has been little study of the tail end of the learning curve in surgical practice, and in fact, there is no definition of exactly where the tail begins and even less information on surgical progress over the course of the tail. In most studies of the tail end, the definition is the moment in time after the steep learning curve has been surpassed. This is generally believed to be anywhere from 35 to 200 cases. $^{32}$ 
Younus et al.

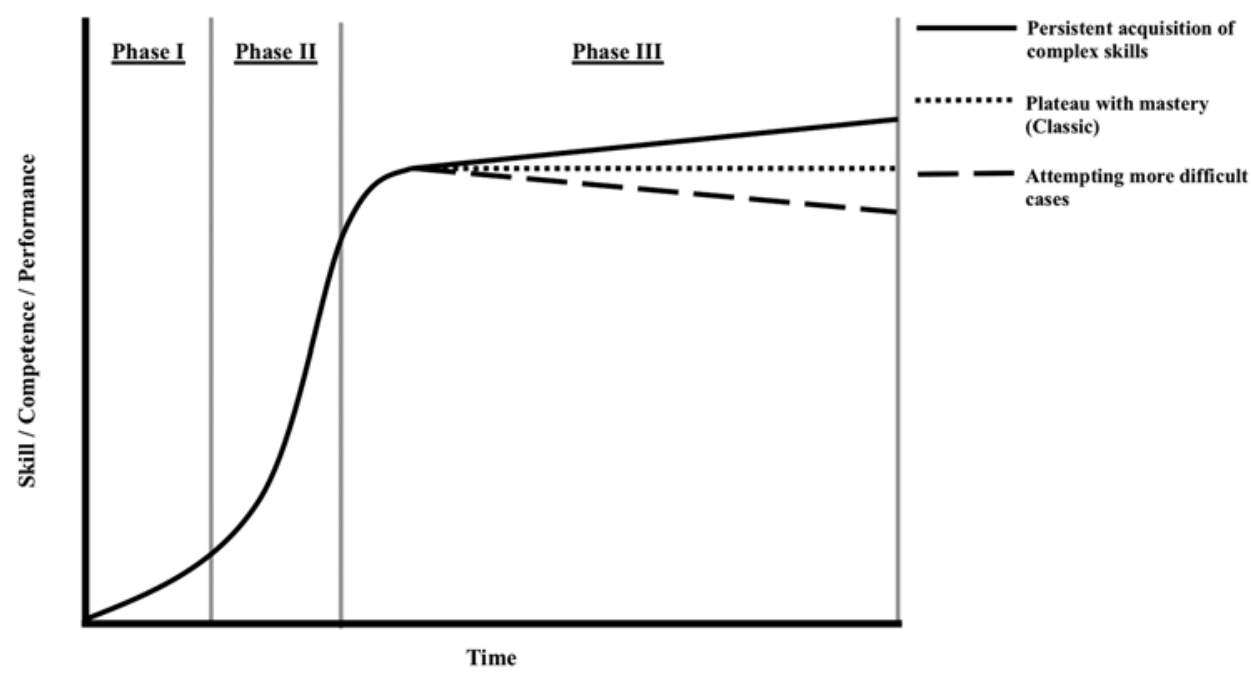

FIG. 3. Three phases of the surgical learning curve. Phase III has three options that vary according to what is being measured. In the classic view, the tail end plateaus as the surgeon masters the technique (dotted line). If procedure length is measured, there can be an increase in the length of procedures as more difficult cases are attempted and there is more time spent on teaching (dashed line). For complex tasks such as achieving a GTR, there is continued learning that may persist indefinitely (solid line).

The assumption is that once the early learning curve is overcome, there exists a flat plateau with little incremental improvement. For example, in studies professing to examine the tail end of the curve, Ooman et al. find the tail end of the learning curve after only 35 laparoscopic pyloromyotomies, and Voitk et al. define the tail of the learning curve after 200 laparoscopic cholecystectomies. ${ }^{29,42}$ These studies do not examine whether incremental learning occurs in the later plateau phase of the learning curve and thus do not really address the length of the tail, but rather only the start of the tail. Moreover, the outcome measures used in these studies were uniquely complication rates, which as we have shown, can certainly plateau.

In oncology, another important endpoint not examined in these studies is extent of resection. The only prior study in ESBS with sufficient cases to address this question for the tail end of the learning curve was one published by Kassam et al. in which they retrospectively analyzed a series of their initial 800 cases of ESBS. This was the first large study to describe the perioperative safety and short-term outcomes of endoscopic endonasal surgery for skull base lesions. ${ }^{12}$ However, this study was specifically concerned with complications and did not examine the learning curve, nor did they measure extent of resection. Complication rates were correlated with case complexity. Although their postoperative CSF leak decreased over time from $15.9 \%$ to $5.4 \%$, this was associated with a specific technical advance, namely the adoption of the vascularized nasoseptal flap.

What are the causes of the long duration of the tail end of the learning curve for GTR in ESBS, why has this not been appreciated in the past, and what are the implications? One explanation of the extended duration of the learning curve for GTR could be the complexity of the task. Removing a meningioma, chordoma, or craniopharyngioma whose margins may be stuck to critical neurovascular structures through a long narrow corridor is certainly challenging, as are many other neurosurgical procedures. Support for this conclusion can be found in a study performed by Subramonian and Muir in which they gave a group of medical students intense surgical training for 12 weeks in open and laparoscopic surgery. ${ }^{40}$ At the end of their training period, while their overall proficiency at both techniques was similar, on detailed analysis of the different components of surgery, the laparoscopic skills were deficient in finer dissection, identification of correct planes, and 2D perception when compared to open surgery, and required more operative time. Hence, depending on the endpoint measured, the learning curve could be considered overcome or still in existence and the complexity of the task dictated the length of the learning curve. Clearly the S-shape of the surgical learning curve is an idealized version of reality and for the most complex aspects of any surgical procedure, the tail end of the learning curve likely continues to slope upward for several years or even decades (Fig. 3). The most relevant publication in the neurosurgical literature assessed the ability of a surgeon to estimate the extent of resection during glioma surgery. ${ }^{23}$ The senior author demonstrated that over a 17-year period, this ability increased almost linearly throughout the entire period of observation, indicating that surgical judgment for complex tasks is honed over periods of decades and not just months or years. The reason there has been little documentation of such a long slow trend in improving outcomes can be attributed to the fact that most studies examine endpoints such as complications and length of surgery rather than extent of resection, and the former reach an earlier plateau or have a decline rather than an increase. Moreover, in a mature surgical practice GTR rates are generally high and small increases would require very large numbers of patients to achieve statistical significance. Interestingly, we also found increases in the rate of GTR for our pituitary adenomas. These are considered easier to remove than meningiomas, craniopha- 
ryngiomas, or chordomas, and indicate that perhaps such high complexity is not required for a long incremental tail in improvement. Indeed, the rate of GTR for adenomas was already high in the first 500 cases, yet continued to increase even after several hundred cases. Given the high numbers of cases of adenomas in our study, we were able to find statistical significance. Likewise, hormonal cure in secreting adenomas increased over time, indicating that the ability to achieve an extracapsular plane and remove the tumors en bloc requires hundreds of cases to achieve proficiency. The same can be said about the reduction in intraoperative CSF leak in our adenoma cases. Even after 700 cases, this rate decreased as we became more and more skilled at finding the pseudocapsule and maintaining an intact diaphragma sella without compromising GTR. For lower-volume pathologies, finding a significant increase in GTR rates in the tail would take a very large numbers of cases. Such is the case with meningiomas, in which we saw the rate of GTR increase from $55 \%$ to $70 \%$ but were not able to show statistical significance due to the small number of cases performed.

\section{Implications of the Long Tail End of the Learning Curve}

The existence of a long, drawn-out tail of a surgical learning curve for specific endpoints such as GTR has profound implications for clinical trial design as well as health care delivery and reimbursement. Most clinical trials begin to enroll patients once surgeons are believed to have adequate training to achieve equipoise. While such a long learning curve may complicate such trials and potentially render them uninterpretable, it can be assumed that all complex surgical approaches likely have equally long tails that may balance out. More importantly, such trials may have to examine individual surgeon's learning curves throughout the entire length of their enrollment to assess the impact of their unique learning curve. Another important ramification of this study speaks to the increasing understanding of surgeon experience and outcome and the call for centers of excellence where certain pathologies should be centralized in the hands of high-volume surgeons. ${ }^{2}$ It is well accepted that with increasing volume, individual surgeons and centers report improved outcomes. $^{2}$ However, centralization is controversial because the underlying assumption and perhaps myth of medical training is that once a surgeon has emerged from a residency program, they are adequately trained to perform all procedures regardless of complexity. ${ }^{2}$ Government bureaucrats, insurance company executives, and hospital administrators often fail to account for surgical experience and expertise when directing patients to the most expedient and cheapest option to suit their prioritized financial endpoints. Our data indicate that not only is there a minimal threshold to become a center of excellence, but there are also incrementally higher degrees of excellence that likely evolve over the lifetime of the surgeon.

\section{Evolution of Skull Base Closure}

Numerous studies comparing EEA to transcranial surgery have demonstrated that in experienced hands, EEA can offer high rates of resection with low complications. ${ }^{35}$ However, even after hundreds of cases, there are subtle changes in practice that indicate how the field is evolving. For example, our CSF leak rate was fairly constant and did not markedly improve over time, although our use of lumbar drains decreased. Our approach to lumbar drains is that they play an important role in preventing CSF leaks in high-risk cases. This conclusion is borne out by the randomized study performed by the Pittsburgh group as well as our own study in patients with high BMIs. ${ }^{3,45}$ Over time, the cases that were believed to be high risk were mostly intradural cases such as meningiomas, craniopharyngiomas, some chordomas, and giant adenomas, as well as lowerrisk cases in patients with very high BMIs such as meningoencephaloceles. We also moved away from fat graft placement in intradural cases relying on the gasket and the nasoseptal flap, and moved away from using the gasket by itself and always combined the gasket with the nasoseptal flap. These subtle shifts in practice did not dramatically alter our rates of CSF leak but rather made the closure algorithm simpler and easier to implement.

\section{Limitations}

The limitations of this study are its retrospective design involving a single institution, which is subject to imprecision of the medical record system and inherent bias. However, this is a consecutive series of cases and the database was created prospectively, so no cases are missing.

Another potential limitation of this study is the arbitrary decision to start the data collection at 200 cases to eliminate the initial phases of the learning curve. Although the exact length of phase I and phase II of the surgical learning curve (Fig. 3) cannot be determined, 200 cases is the upper limit of most studies of the surgical learning curve and we wanted to be conservative. ${ }^{32}$ Moreover, the division into the first 500 and second 500 cases is also arbitrary but seemed like a reasonable cutoff. Analysis based on quartiles might yield different results but would be equally arbitrary and further reduce our numbers and any potentially statistically significant results.

\section{Conclusions}

ESBS is becoming increasingly safe and effective over time. With practice, experience, and an algorithm for closure based on pathology, location, and presence of a leak, rates of CSF leak and complications can be quite low. Nevertheless, even after several hundred cases, there are noticeable improvements in outcome, particularly extent of resection and hormonal cure for more complex tumors, indicating a long, albeit flatter tail end of the learning curve. Our study demonstrates that contrary to popular belief, the surgical learning curve does not plateau but can continue for several years when complex endpoints are considered. These findings may have dramatic implications for clinical trial design, surgical education, government policy, and patient safety measures.

\section{References}

1. Bokhari MB, Patel CB, Ramos-Valadez DI, Ragupathi M, Haas EM: Learning curve for robotic-assisted laparoscopic colorectal surgery. Surg Endosc 25:855-860, 2011 
2. Casanueva FF, Barkan AL, Buchfelder M, Klibanski A, Laws ER, Loeffler JS, et al: Criteria for the definition of Pituitary Tumor Centers of Excellence (PTCOE): a Pituitary Society statement. Pituitary 20:489-498, 2017

3. Cohen S, Jones SH, Dhandapani S, Negm HM, Anand VK, Schwartz TH: Lumbar drains decrease the risk of postoperative cerebrospinal fluid leak following endonasal endoscopic surgery for suprasellar meningiomas in patients with high body mass index. Oper Neurosurg (Hagerstown) 14:66-71, 2018

4. Conger A, Zhao F, Wang X, Eisenberg A, Griffiths C, Esposito $\mathrm{F}$, et al: Evolution of the graded repair of CSF leaks and skull base defects in endonasal endoscopic tumor surgery: trends in repair failure and meningitis rates in 509 patients. J Neurosurg 130:861-875, 2018

5. Ding H, Gu Y, Zhang X, Xie T, Liu T, Hu F, et al: Learning curve for the endoscopic endonasal approach for suprasellar craniopharyngiomas. J Clin Neurosci 42:209-216, 2017

6. Foo CC, Law WL: The learning curve of robotic-assisted low rectal resection of a novice rectal surgeon. World J Surg 40:456-462, 2016

7. Forbes N, Mohamed R, Raman M: Learning curve for endoscopy training: is it all about numbers? Best Pract Res Clin Gastroenterol 30:349-356, 2016

8. Garcia-Navarro V, Anand VK, Schwartz TH: Gasket seal closure for extended endonasal endoscopic skull base surgery: efficacy in a large case series. World Neurosurg 80:563-568, 2013

9. Hopper AN, Jamison MH, Lewis WG: Learning curves in surgical practice. Postgrad Med J 83:777-779, 2007

10. Jakimovski D, Bonci G, Attia M, Shao H, Hofstetter C, Tsiouris AJ, et al: Incidence and significance of intraoperative cerebrospinal fluid leak in endoscopic pituitary surgery using intrathecal fluorescein. World Neurosurg 82:e513e523, 2014

11. Jiménez-Rodríguez RM, Díaz-Pavón JM, de la Portilla de Juan F, Prendes-Sillero E, Dussort HC, Padillo J: Learning curve for robotic-assisted laparoscopic rectal cancer surgery. Int J Colorectal Dis 28:815-821, 2013

12. Kassam AB, Prevedello DM, Carrau RL, Snyderman CH, Thomas A, Gardner P, et al: Endoscopic endonasal skull base surgery: analysis of complications in the authors' initial 800 patients. J Neurosurg 114:1544-1568, 2011

13. Khan N, Abboudi H, Khan MS, Dasgupta P, Ahmed K: Measuring the surgical 'learning curve': methods, variables and competency. BJU Int 113:504-508, 2014

14. Khan OH, Anand VK, Schwartz TH: Endoscopic endonasal resection of skull base meningiomas: the significance of a "cortical cuff" and brain edema compared with careful case selection and surgical experience in predicting morbidity and extent of resection. Neurosurg Focus 37(4):E7, 2014

15. Komotar RJ, Starke RM, Raper DM, Anand VK, Schwartz TH: The endoscope-assisted ventral approach compared with open microscope-assisted surgery for clival chordomas. World Neurosurg 76:318-327, 259-262, 2011

16. Komotar RJ, Starke RM, Raper DM, Anand VK, Schwartz TH: Endoscopic endonasal compared with microscopic transsphenoidal and open transcranial resection of craniopharyngiomas. World Neurosurg 77:329-341, 2012

17. Komotar RJ, Starke RM, Raper DM, Anand VK, Schwartz TH: Endoscopic endonasal compared with microscopic transsphenoidal and open transcranial resection of giant pituitary adenomas. Pituitary 15:150-159, 2012

18. Komotar RJ, Starke RM, Raper DM, Anand VK, Schwartz TH: Endoscopic endonasal versus open transcranial resection of anterior midline skull base meningiomas. World Neurosurg 77:713-724, 2012

19. Komotar RJ, Starke RM, Raper DM, Anand VK, Schwartz TH: Endoscopic skull base surgery: a comprehensive com- parison with open transcranial approaches. Br J Neurosurg 26:637-648, 2012

20. Koutourousiou M, Gardner PA, Tormenti MJ, Henry SL, Stefko ST, Kassam AB, et al: Endoscopic endonasal approach for resection of cranial base chordomas: outcomes and learning curve. Neurosurgery 71:614-625, 2012

21. Kshettry VR, Do H, Elshazly K, Farrell CJ, Nyquist G, Rosen $\mathrm{M}$, et al: The learning curve in endoscopic endonasal resection of craniopharyngiomas. Neurosurg Focus 41(6):E9, 2016

22. Kubat E, Hansen N, Nguyen H, Wren SM, Eisenberg D: Urgent and elective robotic single-site cholecystectomy: analysis and learning curve of 150 consecutive cases. J Laparoendosc Adv Surg Tech A 26:185-191, 2016

23. Lau D, Hervey-Jumper SL, Han SJ, Berger MS: Intraoperative perception and estimates on extent of resection during awake glioma surgery: overcoming the learning curve. $\mathbf{J}$ Neurosurg 128:1410-1418, 2018

24. Leng LZ, Brown S, Anand VK, Schwartz TH: "Gasket-seal" watertight closure in minimal-access endoscopic cranial base surgery. Neurosurgery 62:ONSE342-ONSE343, 2008

25. Mascarenhas L, Moshel YA, Bayad F, Szentirmai O, Salek AA, Leng LZ, et al: The transplanum transtuberculum approaches for suprasellar and sellar-suprasellar lesions: avoidance of cerebrospinal fluid leak and lessons learned. World Neurosurg 82:186-195, 2014

26. McCoul ED, Anand VK, Singh A, Nyquist GG, Schaberg MR, Schwartz TH: Long-term effectiveness of a reconstructive protocol using the nasoseptal flap after endoscopic skull base surgery. World Neurosurg 81:136-143, 2014

27. Nix P, Alavi SA, Tyagi A, Phillips N: Endoscopic repair of the anterior skull base-is there a learning curve? $\mathbf{B r} \mathbf{J}$ Neurosurg 32:407-411, 2018

28. Nyquist GG, Anand VK, Singh A, Schwartz TH: Janus flap: bilateral nasoseptal flaps for anterior skull base reconstruction. Otolaryngol Head Neck Surg 142:327-331, 2010

29. Oomen M, Bakx R, Peeters B, Boersma D, Wijnen M, Heij H: Laparoscopic pyloromyotomy, the tail of the learning curve. Surg Endosc 27:3705-3709, 2013

30. Ottenhausen M, Banu MA, Placantonakis DG, Tsiouris AJ, Khan OH, Anand VK, et al: Endoscopic endonasal resection of suprasellar meningiomas: the importance of case selection and experience in determining extent of resection, visual improvement, and complications. World Neurosurg 82:442-449, 2014

31. Patel KS, Komotar RJ, Szentirmai O, Moussazadeh N, Raper DM, Starke RM, et al: Case-specific protocol to reduce cerebrospinal fluid leakage after endonasal endoscopic surgery. J Neurosurg 119:661-668, 2013

32. Pernar LIM, Robertson FC, Tavakkoli A, Sheu EG, Brooks DC, Smink DS: An appraisal of the learning curve in robotic general surgery. Surg Endosc 31:4583-4596, 2017

33. Qureshi T, Chaus F, Fogg L, Dasgupta M, Straus D, Byrne RW: Learning curve for the transsphenoidal endoscopic endonasal approach to pituitary tumors. Br J Neurosurg 30:637-642, 2016

34. Schwartz TH, Fraser JF, Brown S, Tabaee A, Kacker A, Anand VK: Endoscopic cranial base surgery: classification of operative approaches. Neurosurgery 62:991-1005, 2008

35. Schwartz TH, Morgenstern PF, Anand VK: Lessons learned in the evolution of endoscopic skull base surgery. J Neurosurg 130:337-346, 2019

36. Shakir M, Boone BA, Polanco PM, Zenati MS, Hogg ME, Tsung A, et al: The learning curve for robotic distal pancreatectomy: an analysis of outcomes of the first 100 consecutive cases at a high-volume pancreatic centre. HPB 17:580586, 2015

37. Shikary T, Andaluz N, Meinzen-Derr J, Edwards C, Theodosopoulos P, Zimmer LA: Operative learning curve after 
transition to endoscopic transsphenoidal pituitary surgery. World Neurosurg 102:608-612, 2017

38. Sng KK, Hara M, Shin JW, Yoo BE, Yang KS, Kim SH: The multiphasic learning curve for robot-assisted rectal surgery. Surg Endosc 27:3297-3307, 2013

39. Snyderman C, Kassam A, Carrau R, Mintz A, Gardner P, Prevedello DM: Acquisition of surgical skills for endonasal skull base surgery: a training program. Laryngoscope 117:699-705, 2007

40. Subramonian K, Muir G: The 'learning curve' in surgery: what is it, how do we measure it and can we influence it? BJU Int 93:1173-1174, 2004

41. Tabaee A, Anand VK, Brown SM, Lin JW, Schwartz TH: Algorithm for reconstruction after endoscopic pituitary and skull base surgery. Laryngoscope 117:1133-1137, 2007

42. Voitk AJ, Tsao SG, Ignatius S: The tail of the learning curve for laparoscopic cholecystectomy. Am J Surg 182:250-253, 2001

43. Wright T: Factors affecting the cost of airplanes. J Aeronaut Sci 3:122-128, 1936

44. Yamaguchi T, Kinugasa Y, Shiomi A, Sato S, Yamakawa Y, Kagawa $\mathrm{H}$, et al: Learning curve for robotic-assisted surgery for rectal cancer: use of the cumulative sum method. Surg Endosc 29:1679-1685, 2015

45. Zwagerman NT, Wang EW, Shin SS, Chang YF, FernandezMiranda JC, Snyderman CH, et al: Does lumbar drainage reduce postoperative cerebrospinal fluid leak after endoscop- ic endonasal skull base surgery? A prospective, randomized controlled trial. J Neurosurg 131:1172-1178, 2019

\section{Disclosures}

The authors report no conflict of interest concerning the materials or methods used in this study or the findings specified in this paper.

\section{Author Contributions}

Conception and design: Schwartz, Younus, Uribe-Cardenas, Morgenstern. Acquisition of data: all authors. Analysis and interpretation of data: Schwartz, Younus, Gerges, UribeCardenas, Morgenstern, Eljalby. Drafting the article: Schwartz, Younus. Critically revising the article: Schwartz, Younus, Gerges. Reviewed submitted version of manuscript: all authors. Approved the final version of the manuscript on behalf of all authors: Schwartz. Statistical analysis: Schwartz, Younus. Administrative/ technical/material support: Tabaee, Greenfield, Kacker, Anand. Study supervision: Schwartz, Younus.

\section{Correspondence}

Theodore H. Schwartz: Weill Cornell Medicine, New York, NY. schwarh@med.cornell.edu. 